\title{
Human influence on tropical cyclone intensity
}

\author{
Adam H. Sobel, ${ }^{1,2 *}$ Suzana J. Camargo, ${ }^{2}$ Timothy M. Hall, ${ }^{3}$ Chia-Ying Lee, ${ }^{4}$ \\ Michael K. Tippett, ${ }^{1,5}$ Allison A. Wing ${ }^{2}$
}

\begin{abstract}
Recent assessments agree that tropical cyclone intensity should increase as the climate warms. Less agreement exists on the detection of recent historical trends in tropical cyclone intensity. We interpret future and recent historical trends by using the theory of potential intensity, which predicts the maximum intensity achievable by a tropical cyclone in a given local environment. Although greenhouse gas-driven warming increases potential intensity, climate model simulations suggest that aerosol cooling has largely canceled that effect over the historical record. Large natural variability complicates analysis of trends, as do poleward shifts in the latitude of maximum intensity. In the absence of strong reductions in greenhouse gas emissions, future greenhouse gas forcing of potential intensity will increasingly dominate over aerosol forcing, leading to substantially larger increases in tropical cyclone intensities.
\end{abstract}

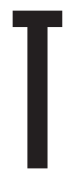
heory and numerical simulations suggest that human emissions of greenhouse gases, acting on their own, should have already caused a small increase in tropical cyclone (TC) intensities globally. The same theory and simulations indicate that we should not expect to be able to discern this increase in recent historical observations because of the confounding influences of aerosol forcing (which acts to oppose greenhouse gas forcing) and large natural variability (which compromises trend detection). Current expectations for the future are that aerosol forcing will remain level or decrease while greenhouse gas forcing continues to increase, leading to considerable increases in TC intensity as the climate warms further. Relatively low confidence in observed trends and greater confidence in projections of future trends are both consistent with our current understanding.

We first review projections of future $\mathrm{TC}$ activity, considering not only intensity but other measures including TC frequency (the number of storms per year), TC-induced precipitation, and coastal flooding. Future projections underpin any discussion of human influence in the present. The influence of greenhouse gas emissions is expected to be greater in the future, and the literature regarding the mechanisms of that influence focuses more on future scenarios. We then discuss recent historical trends in both TC activity and potential intensity (PI), an environmental parameter that encapsulates much of our

\footnotetext{
Department of Applied Physics and Applied Mathematics, Columbia University, New York, NY 10027, USA. ² LamontDoherty Earth Observatory, Columbia University, Palisades, NY 10964, USA. ${ }^{3}$ NASA Goddard Institute for Space Studies, New York, NY 10025, USA. ${ }^{4}$ International Research Institute for Climate and Society, Columbia University, Palisades, NY 10964, USA. ${ }^{5}$ Center of Excellence for Climate Research, Department of Meteorology, King Abdulaziz University, Jeddah, Saudi Arabia. *Corresponding author. Email: ahs129@columbia.edu
}

theoretical understanding of the control that climate exerts on TC intensity.

\section{Projected influence of climate change on tropical cyclones from models and theory}

After an initial period of disagreement [e.g., (1-5)], more recent assessments and reviews are in broad agreement regarding future projections of various aspects of TC activity and the confidence associated with each aspect (6-9). An important source of new results informing the present consensus has been high-resolution global models, which simulate TCs with greater fidelity than did earlier models (10). A parallel development has been a much more nuanced understanding, based on multiple lines of evidence, of the relationship between TCs and their local environment.

PI is a useful parameter for understanding TC intensity as a function of the large-scale environment. It has multiple formulations that differ in detail but are broadly similar; here we use the formulation of Bister and Emanuel (11). The PI is a function of both the sea surface temperature (SST) and the vertical profiles of temperature and humidity in the atmosphere above. The PI is derived from an explicit physical theory that predicts the maximum intensity that a TC can achieve, given those environmental conditions. Although the validity of PI theory has been critiqued on multiple grounds $(12,13)$, it nonetheless appears, under detailed scrutiny, to hold up well enough to be useful (14), and it provides a strong theoretical underpinning for discussions of how tropical cyclones may change with climate.

In the simulations from both the Third $(15,16)$ and the Fifth (17) Coupled Model Intercomparison Projects (CMIP3 and CMIP5), climate models predict robustly that PI should increase in future warming scenarios in most regions where tropical cyclone activity occurs. The eastern part of the North Atlantic, where PI is projected to decrease, is a notable exception. PI essentially measures the degree of disequilibrium between the ocean surface and the atmosphere; a warmer ocean or a cooler atmosphere (in an appropriately generalized sense, accounting for temperature, humidity, and vertical structure from the surface to the lower stratosphere) leads to greater PI. Both models and physical arguments $(16,18,19)$ predict that these differences should increase with climate warming (Fig. 1). The largest predicted increases are on the margins of the tropics, particularly in the Atlantic and Pacific.

Although PI is a prediction only of the maximum intensity that a tropical cyclone can achieve in a given environment, it is expected to provide a useful guide to the statistical distribution of actual intensities achieved by real TCs. Most TCs do not achieve their PI because of a variety of negative influences not fully accounted for by the theory, such as vertical wind shear and entrainment of dry air into the storm [e.g., (20)] or ocean coupling [e.g., (21-23)]. Nonetheless, observational evidence (24-26) and high-resolution numerical simulations $(14,27)$ suggest that changes in PI are associated with changes in the average intensities that storms achieve. We thus expect TC intensities to increase with warming, both on average and at the high end of the scale, so that the strongest future storms will exceed the strength of any in the past. Although factors such as wind shear may change so as to modulate the influence of PI in some regions [e.g., (28)], we expect these influences to be more variable globally, and we assume as a starting point that they will not systematically counteract the global effect of increasing PI. This expectation is consistent, at least qualitatively, with the results of the most convincing numerical simulations, which show TC intensities increasing in a warming climate (29-32).

The frequency of TC occurrence is much less well understood than is TC intensity. About $90 \pm$ 8 TCs form on Earth each year $(33,34)$. In contrast to the situation for intensity, no physical theory predicts this number, even to an order of magnitude, despite intense research activity on mechanisms controlling the genesis of individual TCs [e.g., $(35,36)]$. Subseasonal to interannual variations in TC frequency are widely diagnosed using semi-empirical genesis indices (37-40), but using these to predict future global changes requires a problematic out-of-sample extrapolation $(41,42)$.

Global high-resolution models have tended to simulate reductions in TC frequency under a warming climate $(30,31,43,44)$; the most likely explanations for this behavior at present $(38,42)$ involve an increasing saturation deficit (the difference between actual and saturation specific humidity) as temperature increases and relative humidity stays approximately constant [e.g., (45)]. These arguments have not been adequately developed or tested, however, and some credible models predict increases in TC frequency with warming $(23,46)$. Altogether, the projection that TC frequency will decrease with warming is considerably more uncertain than the projection that TC intensity will increase. 
A ERA-40

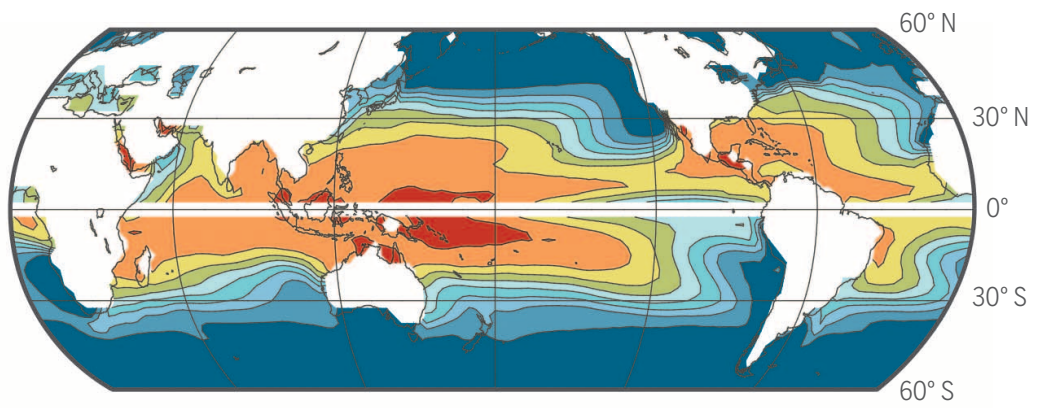

B

CMIP5

historical

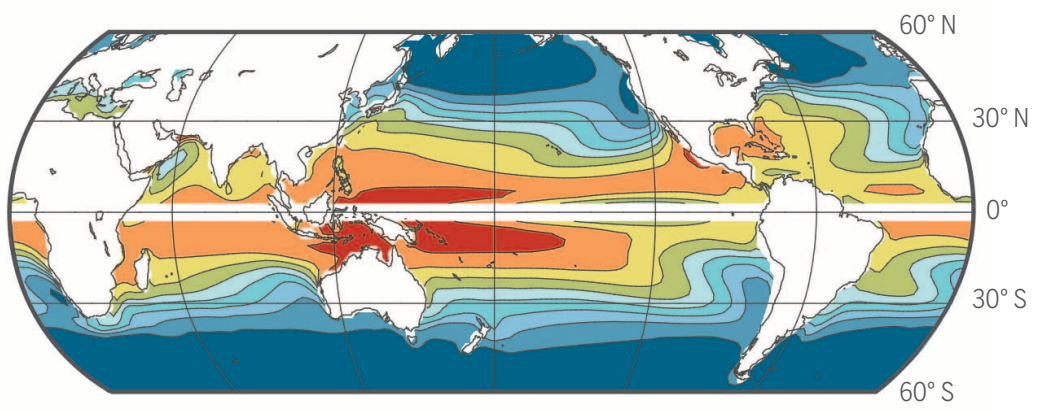

C

CMIP5

RCP8.5

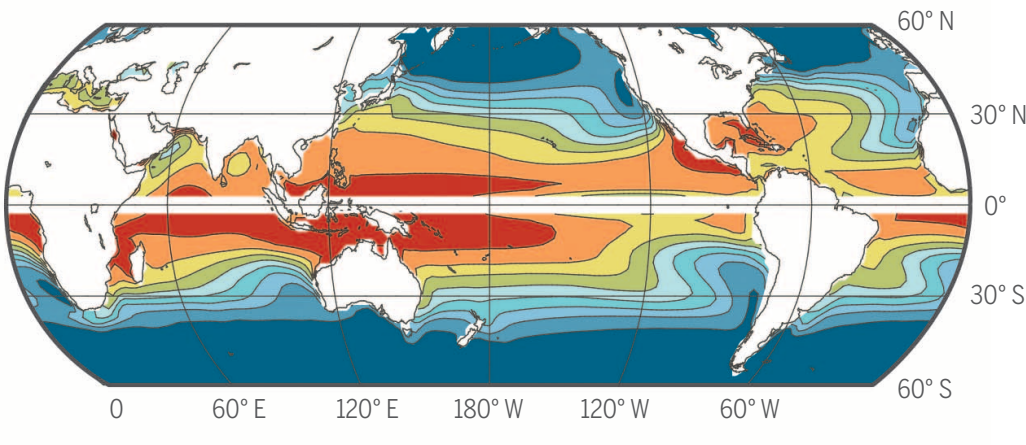

$\mathrm{PI}\left(\mathrm{m} \mathrm{s}^{-1}\right)$

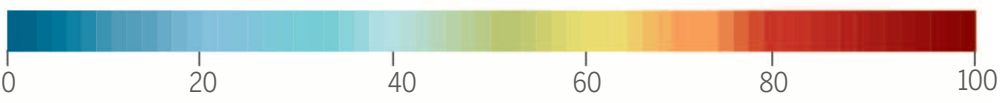

D

RCP8.5

minus

historical

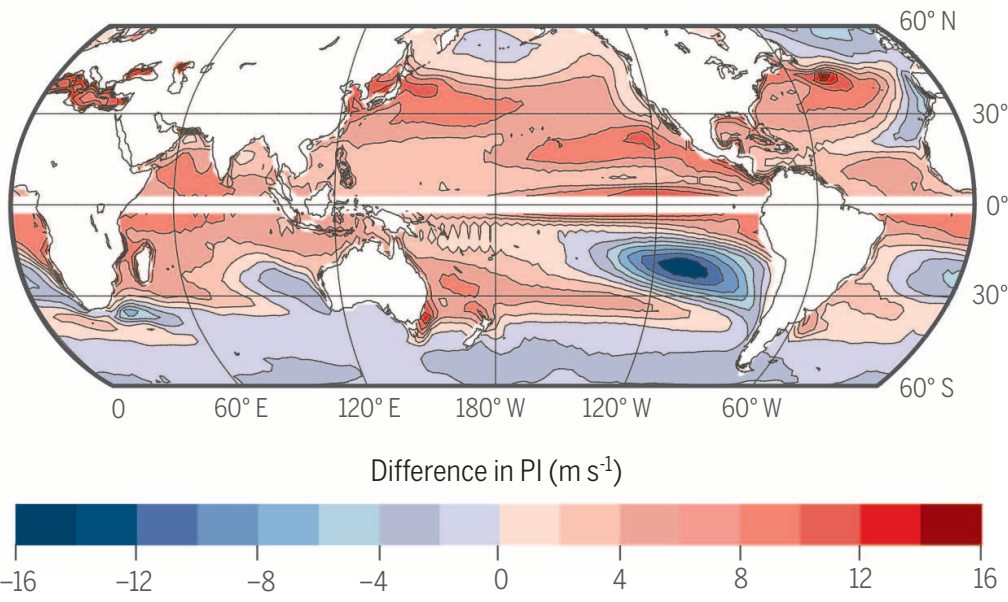

Fig. 1. PI climatology. (A) ERA-40 reanalysis (84) for 1971-2000, (B) CMIP5 historical runs (multimodel mean) for 1971-2000, (C) CMIP5 RCP8.5 projection (multimodel mean) for 2071-2100, and (D) values in (C) minus those in (B). The Northern (Southern) Hemisphere season is June to November (December to May). [Inspired by figure 1 in (72) and figure 4 in (19)]
Some other aspects of TC change associated with climate warming are relatively well understood. Increasing precipitation produced by TCs due to increasing water vapor content is expected with considerable confidence as the climate warms $(6,47,48-50)$. Coastal flooding due to TC-induced storm surge is essentially certain to increase with warming as a consequence of sea level rise $(8,9,51$,$) , possibly compounded$ by increases in storm intensity or frequency [e.g., (52-54)].

\section{Observed trends}

The detection of long-term trends in TC activity has been a subject of considerable debate. The validity of data from the earlier periods in the longest-term observational data sets has been strongly questioned [e.g., (55-58)], making any trends computed from records that include those periods disputable. Large natural variability, including substantial components with decadal and longer frequencies, further confounds trend detection in records, which in many cases are only a few decades long. These difficulties have led to findings of low confidence in observed TC trends in consensus assessment reports $(7,59)$.

Perhaps the most persistent and provocative [though not unchallenged (58)] findings are that intensity increased in the past few decades at the upper end of the observed range, implying an increasing frequency of storms in categories 4 and 5 on the commonly used Saffir-Simpson scale (60-62), and that overall activity increased in the North Atlantic over a period of roughly three decades, beginning in the 1970s $(63,64)$.

The North Atlantic changes are of great regional interest in North America. Their causes and implications for the future are the subject of debate. The increase in TC activity in the late 20th century coincided with both absolute and relative warming of the North Atlantic SST. The absolute warming is likely to continue, whereas the relative warming [which has a stronger influence on PI; for example, (65-67)] is not, at least not at the same pace. This implies that future increases, if they occur at all, will be more gradual. More in-depth arguments focus on the specific reasons for the Atlantic warming and associated PI changes, with roles for radiative forcing from greenhouse gases, aerosols, and ozone depletion, as well as internal variability in the Atlantic basin (19, 67-72).

Recent analyses of trends in the most intense storms continue to show evidence of increases in their numbers, but they do not fully resolve the difficulties posed by the combination of data inhomogeneities and large natural variability. Kossin et al. (62) examined trends in the quantiles of lifetime maximum intensity (LMI) in two different data sets over the period 1982-2009, considering only storms whose LMI was 65 knots or greater (Fig. 2). Over this period, the global LMI distribution assessed from best-track data had positive trends in the mean $\left(2 \mathrm{~m} \mathrm{~s}^{-1}\right.$ decade $\left.{ }^{-1}\right)$ and in its quantiles $\left(>2 \mathrm{~m} \mathrm{~s}^{-1}\right.$ decade $^{-1}$ for quantiles > 0.4). In contrast, the LMI distribution from a novel satellite-based data set, designed to be 
temporally homogeneous, had a mean trend $\left(<1 \mathrm{~m} \mathrm{~s}^{-1}\right.$ decade $\left.^{-1}\right)$ and quantile trends that were insignificant. A discontinuity correction further reduced the trends in the LMI distribution. Holland and Bruyère (73) performed an apparently similar analysis to that of (62) but obtained somewhat different results. They used a climate model-based measure of the anthropogenic influence on global mean temperature, rather than time, as a covariate. They focused on the period 1975-2010, during which that covariate appears to vary close to linearly with time, and found that the proportion of storms reaching categories 4 and 5 increased with the covariate. They obtained this result both when using the best-track data and the satellite-based intensity data set used in (62). Their result thus appears to be inconsistent with the findings of (62), unless their covariate differs substantially from a linear trend, which does not appear to be the case.

Should we expect increases in the frequency of the most intense storms to have occurred by now as a consequence of human-induced global warming? Simple considerations suggest that, given a PI increase, actual intensity changes should be most apparent in the highest quantiles of the intensity distribution (74). TC maximum intensities, when not limited by rapid decreases in PI (such as occurs at landfall, for example), are observed to be uniformly distributed between tropical storm intensity and hurricane intensity and uniformly distributed again (but with a different value of the probability) between hurricane intensity and the local PI $(24,25)$. If the entire PI distribution were to be simply shifted to higher values, the upper bound on TC intensity would increase, whereas the lower bound in typical analyses-the wind speed threshold for either tropical storm or category 1 hurricane intensity, for example-would stay constant. This one-sided expansion of the range in TC intensities would imply larger changes in higher quantiles. This appears to be qualitatively consistent with quantile regression analyses that show significant increases (with time and SST) in the highest quantiles but little or no increase in lower quantiles $(61,62)$.

Interpretation of any observed intensity increases along these lines is confounded, however, by uncertainties in PI trends. Robustly detectable trends in basin-average PI are found only in the North Atlantic, where both surface warming and, to some extent, tropical tropopause cooling have contributed to an increase in PI between 1980 and $2013(70,75)$. Elsewhere, there are few statistically significant trends and large disagreements between data sets (75-77), reflecting the uncertainties in tropospheric temperature trends and the limitations of reanalysis and radiosonde data.

\section{The anthropogenic signal at present}

As described above, there remains some disagreement between studies regarding recent historical trends in TC intensity. Similar inconsistency in PI trends from different data sets (outside the Atlantic) weakens our expectation on physical grounds that intensities should have increased. Even if we were to draw the conclusion that our confidence in these historical trends should be low, however, it would be inappropriate to go on to conclude that there is no human influence on TCs at present. To draw that conclusion would be a type II statistical error, conflating absence of evidence with evidence of absence.

Models and theory indicate that human emissions of greenhouse gases should already have caused modest increases in PI on the global scale compared with what would have occurred in the absence of those emissions. Figure 3 shows trends in PI predicted by CMIP5 climate models. These results are from simulations of the historical period, using all forcings (natural and anthropogenic), greenhouse gases only, and aerosols only. Details of the simulations and the calculations can be found in (72), the authors of which performed similar analyses for the North Atlantic; these differ only in that we show results for the entire Northern and Southern Hemispheres.

In these simulations, greenhouse gas and aerosol forcings have approximately equal and opposite influences on PI, resulting in no significant trend, until the most recent period, when the aerosol forcing stops increasing (78) while the greenhouse gas forcing continues to increase. This is the case although the average aerosol forcing-which, including cloud-aerosol effects and comparing the end of the period with the beginning, is on the order of $1 \mathrm{Wm}^{-2}$ [e.g., $(79,80)]$-is only about half the greenhouse gas forcing, so that the net forcing is positive and results in significant SST trends, even as it has little effect on PI. We expect aerosols to influence surface temperature primarily by reducing the shortwave radiative energy flux, whereas greenhouse gases do so by increasing the longwave flux. Single-column model calculations [figure $2 \mathrm{~b}$ in (18)] suggest that shortwave forcing is more effective than longwave forcing, by about a factor of 2, at changing PI per unit SST change. The close cancellation between the two influences on PI over most of the historical record in these simulations appears broadly consistent with our expectations, given the model inputs. [Whether these aerosol forcings are correct is another question; Stevens (80) argued that they may be overestimates. We do not consider this important question here.]

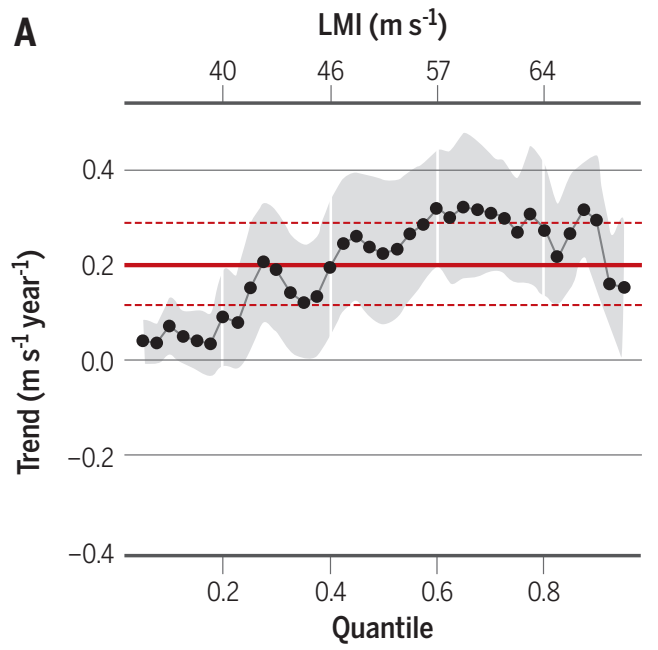

Fig. 2. Global trends in the LMI quantiles of storms that achieved hurricane strength (LMI $\geq 33 \mathrm{~m} \mathrm{~s}^{-1}$ ) in the period 1982-2009. The left panel shows trends in the best-track data, the middle panel shows trends in the ADT-HURSAT (Advanced Dvorak Technique-Hurricane Satellite) record without an additional homogenization step to account for a discontinuity in the satellite data, and the right panel shows trends in the ADT-HURSAT record with the additional homogenization correction. The black dots represent the trends
B $\quad \operatorname{LMI}\left(\mathrm{m} \mathrm{s}^{-1}\right)$
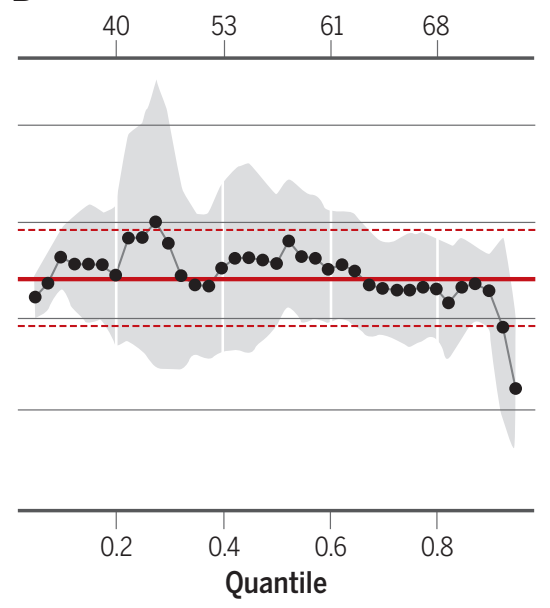
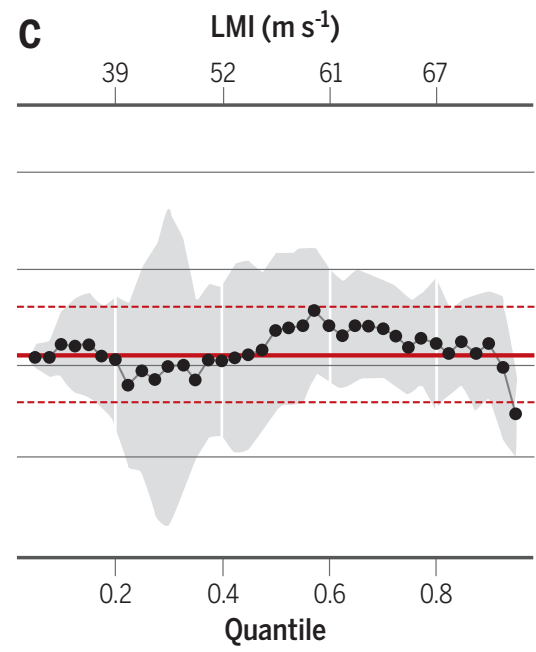

in the quantiles of the LMI distribution from 0.05 to 0.95 in steps of 0.025 . Shading represents pointwise $95 \%$ confidence (two-tailed). The red solid line shows the (constant value) trend in the mean, as measured by ordinary least squares regression, and the red dashed lines show the confidence interval. The top axis shows the LMI values associated with the quantiles along the bottom axis. [From (62), used with permission (copyright American Meteorological Society)] 
A Northern Hemisphere (June to November)

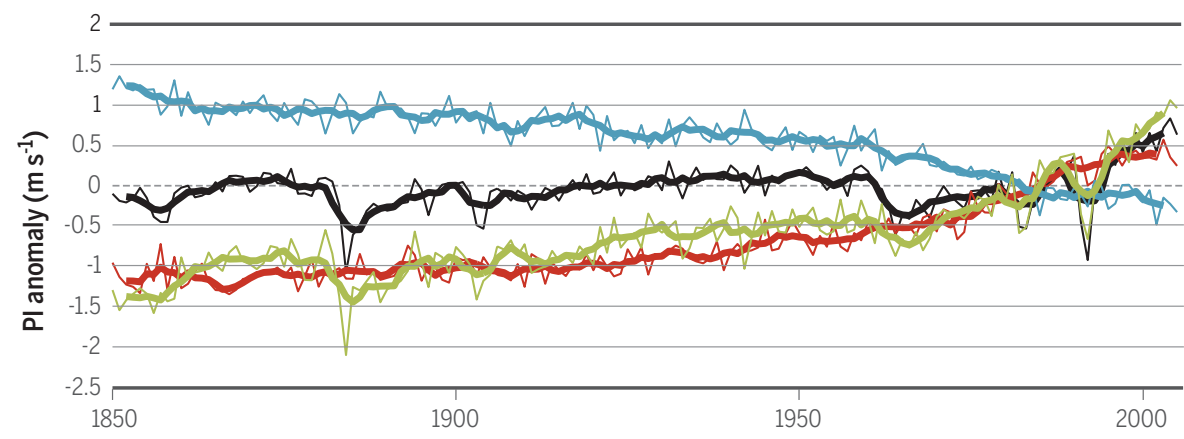

B Southern Hemisphere (December to May)

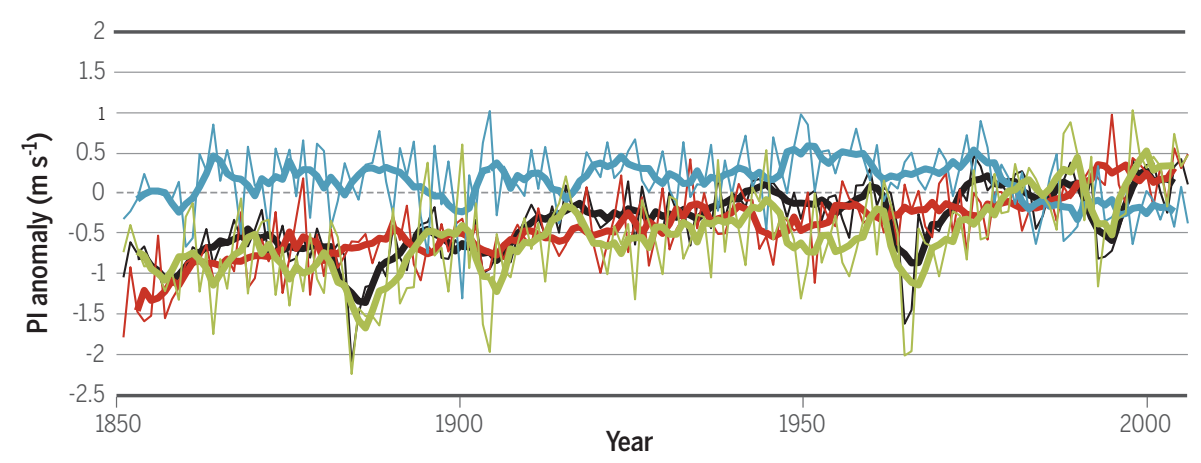

Fig. 3. PI time series from CMIP5 historical runs with all forcings, greenhouse gas-only (GHG) runs, aerosol-only runs, and the difference between the historical and aerosol-only runs (HistAer). (A) Northern Hemisphere $\left(0^{\circ} \mathrm{N}\right.$ to $\left.40^{\circ} \mathrm{N}\right)$. (B) Southern Hemisphere $\left(0^{\circ} \mathrm{S}\right.$ to $\left.40^{\circ} \mathrm{S}\right)$. The thin lines show the multimodel mean for each season, and the thick lines show the 5-year running mean.

Aerosol lifetimes in the atmosphere are much shorter than those of the most important anthropogenic greenhouse gases, and future projection scenarios assume that greenhouse warming will exceed aerosol cooling in the future to an increasingly greater extent than in the past, unless very strong reductions in greenhouse gas emissions are implemented soon (81). We thus take the greenhouse gas-driven component of the PI perturbation in the present to be representative of the human influence as it will be increasingly manifest in the future.

When we ask whether there is a human influence on TC activity in the present, we should not stop at detection of trends with a confidence level of $95 \%$ (or any other specific level) against a null hypothesis of no trend. We might better ask whether the observations are consistent with less naive hypotheses based on models and theory. One such hypothesis might be based on PI. We might assume that on average, LMI is uniformly distributed between a lower bound and the PI, following (24). Kossin et al. (62) constructed a stochastic model based on this assumption; they showed that even in the presence of PI trends larger than those evident in observations and CMIP projections, trends in PI and the LMI distribution would be difficult to detect given the length of the reliable historical record, though trends in the most extreme part of the LMI distribution are more likely to be detected than trends in the middle of the distribution.

We might go even further and construct a similar null hypothesis for a bulk measure of TC activity such as the power dissipation index (PDI), defined as the cubed maximum wind speed of all storms integrated over their lifetimes and added together. If we neglect all variations in storm lifetime, storm frequency, and geographic storm-track distribution, we can construct a simple proxy, PDI = $c\left\langle\mathrm{PI}^{3}\right\rangle$, where the angle brackets represent basin averages and $c$ is a constant chosen to fit the recent historical average. [An accumulated cyclone energy (ACE) proxy would be the same, except with PI squared rather than cubed.] We do not claim that this is a correct model, just that it is a better null hypothesis than zero trend. The neglect of projected storm frequency changes might be justified as a starting point, given the lower confidence in these changes compared with those in intensity. More sophisticated hypo- theses could be based on results from simulations of TCs in high-resolution global models, for example, or could incorporate projections of TC frequency change.

The lack of consistently significant trends in PI (outside the North Atlantic), in either observations or numerical simulations of the historical period, leads us to expect no trend in PDI under our simple null hypothesis. The CMIP5 simulations indicate that the lack of a trend is due to cancellation of aerosol and greenhouse gas effects. Even if the aerosol effects were entirely absent, however, trend detection would be challenged by the large natural variability.

We show in Fig. 4 the observed PDI in the Northern Hemisphere for the period 1950-2014, superimposed on the simple PI-based proxy described above, which we calculated by using the same CMIP5 simulations as in Fig. 3 for the historical period and the representative concentration pathway 8.5 (RCP8.5) scenario (81) for the future. Using this simple proxy as a baseline measure of our expectations, we would not expect to detect significant trends in PDI over the historical period, considering both the small trend in the PI-based proxy for PDI and the large variability in observed PDI (the modelbased estimates have little variability because they are both basin and ensemble averages). Even in the absence of aerosol forcing, the trends would have been small compared with the shorterterm variability. These small and difficult-to-detect trends are is entirely consistent, however, with greater projected increases in PDI over the course of the 21st century under RCP8.5. The future trend in the PI-based proxy for PDI, shown in Fig. 4, is not a prediction for PDI, because multiple factors other than PI influence PDI (or any other bulk measure of TC activity) and are not accounted for by our simple proxy measure. The figure simply makes the general point that small (and thus difficult-to-detect) changes in TC activity up to the

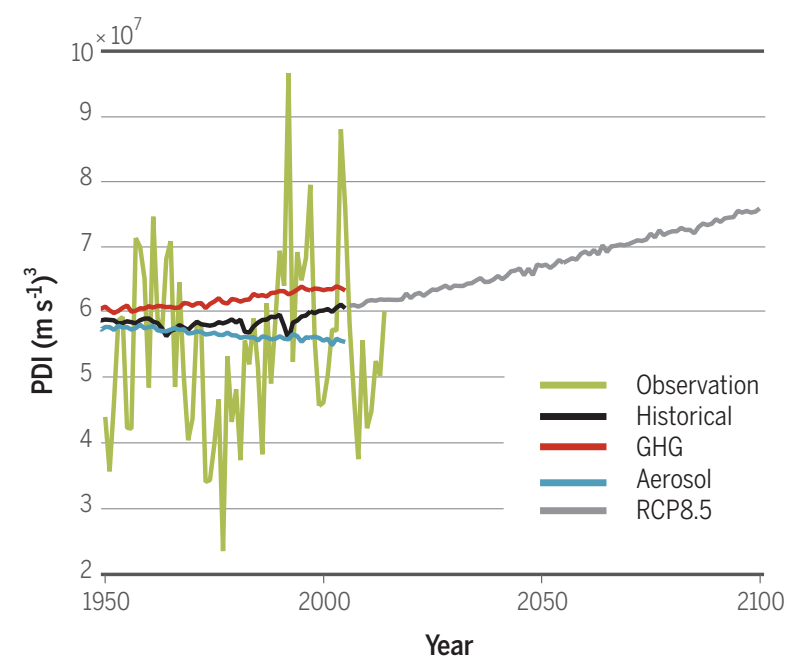

Fig. 4. Observed and proxy PDI for the Northern Hemisphere. The proxy was constructed from the basin- and ensemble-mean PI distribution, using CMIP5 simulations for the historical period (as in Fig. 3) and the RCP8.5 scenario for the future. 
present and substantially larger changes in the future are both consistent with control of TC intensity (as measured by PI) by the large-scale environment.

Assuming that the average intensity of real TCs scales with basin-wide PI, as our simple proxy does, implies an assumption that TC tracks sample the PI distribution within the basin in the same way over time. Observed trends in the latitude of LMI have been detected, however, challenging this assumption and complicating the interpretation of both historical PI trends and future projections. The results of (82) indicate that in the recent historical past, TC tracks have shifted systematically poleward to regions of lower PI, to an extent that approximately compensates for the PI increases at fixed locations, so that the actual PI experienced by the storms has stayed approximately constant, despite basinwide increases (77). It is not clear whether the poleward shift is a response to radiative forcing, but simulations for the western North Pacific suggest that it is, at least in part (83). The fact that projections show the largest increases in PI on the margins of the tropics (Fig. 1) appears to be consistent with this.

Even if future PI increases are accompanied by poleward shifts in LMI to the same extent as in the recent historical record, however, TC statistics will change, whether or not those changes are manifest in bulk statistics such as basin-wide ACE or PDI. Regions poleward of those where historical TC activity has been greatest would see substantial increases in activity. And at any fixed position, PI increases are still expected to lead to intensity increases for storms at that position, absent any other predictable countervailing change (e.g., increasing wind shear). The expectation of unprecedentedly strong future storms remains justifiable.

\section{Conclusions}

We expect, based on a broad understanding informed by observations, theory, and numerical models, that tropical cyclone intensities should increase as the climate warms in response to human emissions of greenhouse gases. We have lower confidence, on the other hand, in recent historical trends in the actual and potential intensities of TCs (in basins other than the North Atlantic). These two conclusions are consistent with the idea that, in the absence of other systematic global influences, global tropical cyclone intensities (as measured by PI) are controlled by the large-scale environment.

PI trends themselves are subject to considerable uncertainty, with different observational data sets showing disagreement, particularly outside the North Atlantic. Climate model simulations indicate that during the late 20th century, greenhouse gas and aerosol radiative forcing had opposite and, until very recently, largely cancelling effects on PI. This cancellation renders radiatively forced trends in PI and actual intensity small and thus difficult to detect in the presence of large natural variability. Detection of trends in actual intensity is further complicated by data inhomogeneities and other observational limitations and by systematic poleward shifts in the storm tracks.

As the 21st century proceeds, we expect greenhouse gas warming to further outpace aerosol cooling and PI increases to exceed those observed to date. TC intensities at any given fixed location should increase accordingly, on average; simulations suggest trends on the order of $1 \mathrm{~m} \mathrm{~s}^{-1}$ decade $^{-1}$ at the high end. If poleward shifts continue, these increases will be manifest in increases in activity at the poleward margins of TC basins, as well as in the occurrence of more intense storms (if perhaps fewer storms overall) in the historical cores of the basins.

These expectations could turn out to be incorrect because of unforeseen factors or inadequacies in our understanding. But the relatively low confidence in the detection of historical trends is not evidence of any such inadequacies.

\section{REFERENCES AND NOTES}

1. S. B. Idso, R. C. Balling Jr., R. S. Cerveny, Meteorol. Atmos. Phys. 42, 259-263 (1990).

2. A. J. Broccoli, S. Manabe, Geophys. Res. Lett. 17, 1917-1920 (1990)

3. J. L. Evans, R. J. Allan, Int. J. Climatol. 12, 611-623 (1992)

4. J. Lighthill et al., Bull. Am. Meteorol. Soc. 75, 2147-2157 (1994).

5. L. Bengtsson, M. Botzet, M. Esch, Tellus 48A, 57-73 (1996).

6. T. R. Knutson et al., Nat. Geosci. 3, 157-163 (2010).

7. S. I. Seneviratne, N. Nicholls, D. Easterling, C. M. Goodess, S. Kanae, J. Kossin, Y. Luo, J. Marengo, K. McInnes, M. Rahimi, M. Reichstein, A. Sorteberg, C. Vera, X. Zhang, "Changes in climate extremes and their impacts on the natural physical environment," in Managing the Risks of Extreme Events and Disasters to Advance Climate Change Adaptation. A Special Report of Working Groups I and II of the Intergovernmental Panel on Climate Change, C. B. Field et al., Eds. (Cambridge Univ. Press, 2012), pp. 109-230.

8. Intergovernmental Panel on Climate Change, Climate Change 2013: The Physical Science Basis. Contribution of Working Group I to the Fifth Assessment Report of the Intergovernmental Panel on Climate Change, T. F. Stocker et al., Eds. (Cambridge Univ. Press, 2013).

9. K. J. E. Walsh et al., WIREs Clim. Change 7, 65-89 (2016).

10. S. J. Camargo, A. A. Wing, WIREs Clim. Change 7, 211-237 (2016).

11. M. Bister, K. A. Emanuel, J. Geophys. Res. 107, 4801 (2002)

12. J. Persing. M. T. Montgomery, J. Atmos. Sci. 60, 2349-2371 (2003).

13. R. K. Smith, M. T. Montgomery, S. Vogl, Q. J. R. Meteorol. Soc 134, 551-561 (2008)

14. G. H. Bryan, R. Rotunno, Mon. Weather Rev. 137, 1770-1789 (2009).

15. G. A. Vecchi, B. J. Soden, Nature 450, 1066-1070 (2007)

16. J. Yu, Y. Wang, K. Hamilton, J. Clim. 23, 1354-1373 (2010).

17. S. J. Camargo, J. Clim. 26, 9880-9902 (2013).

18. K. Emanuel, A. Sobel, J. Adv. Model. Earth Syst. 5, 447-458 (2013).

19. L. M. Polvani, S. J. Camargo, R. R. Garcia, J. Clim. 29 2275-2289 (2016)

20. B. Tang, K. Emanuel, J. Atmos. Sci. 67, 1817-1830 (2010).

21. I.-I. Lin et al., Geophys. Res. Lett. 40, 1878-1882 (2013).

22. P. Huang, I.-I. Lin, C. Chou, R.-H. Huang, Nat. Commun. 6, 7188 (2015).

23. K. Emanuel, J. Clim. 28, 8165-8170 (2015).

24. K. A. Emanuel, Mon. Weather Rev. 128, 1139-1152 (2000).

25. A. A. Wing, A. H. Sobel, S. J. Camargo, Geophys. Res. Lett. 34 L08810 (2007).

26. J. P. Kossin, S. J. Camargo, Clim. Change 97, 329-337 (2009).

27. S. Wang, S. J. Camargo, A. H. Sobel, L. M. Polvani, J. Atmos. Sci. 71, 4333-4348 (2014)

28. G. A. Vecchi, B. J. Soden, Geophys. Res. Lett. 34, L08702 (2007).

29. M. A. Bender et al., Science 327, 454-458 (2010).

30. H. Murakami et al., J. Clim. 25, 3237-3260 (2012).

31. T. R. Knutson et al, J Clim. 28, 7203-7224 (2015).

32. J. V. Manganello et al., J. Clim. 27, $7622-7646$ (2014).

33. W. M. Frank, G. S. Young, Mon. Weather Rev. 135, 3587-3598 (2007)

34. B. Wang, Y. Yang, Q.-H. Ding, H. Murakami, F. Huang, Geophys. Res. Lett. 37, L07704 (2010).

35. D. J. Raymond, S. L. Sessions, Ž. Fuchs, Q. J. R. Meteorol. Soc. 133, 1743-1754 (2007)

36. T. J. Dunkerton, M. T. Montgomery, Z. Wang, Atmos. Chem. Phys. 9, 5587-5646 (2009).

37. K. A. Emanuel, D. S. Nolan, in Proceedings of 26th Conference on Hurricanes and Tropical Meteorology (American Meteorological Society, 2004), pp. 240-241.
38. K. Emanuel, J. Adv. Model. Earth Syst. 2, 1 (2010).

39. M. K. Tippett, S. J. Camargo, A. H. Sobel, J. Clim. 24, 2335-2357 (2011).

40. C. L. Bruyère, G. J. Holland, E. Towler, J. Clim. 25, 8611-8626 (2012),

41. S. J. Camargo, A. H. Sobel, A. G. Barnston, K. A. Emanuel, Tellus 59A, 428-443 (2007)

42. S. J. Camargo, M. K. Tippett, A. H. Sobel, G. A. Vecchi, M. Zhao, J. Clim. 27, 9171-9196 (2014)

43. K. Emanuel, R. Sundararajan, J. Williams, Bull. Am. Meteorol. Soc. 89, 347-367 (2008)

44. M. Wehner et al., J. Clim. 28, 3905-3925 (2015).

45. I. M. Held, B. J. Soden, J. Clim. 19, 5686-5699 (2006)

46. K. A. Emanuel, Proc. Natl. Acad. Sci. U.S.A. 110, 12219-12224 (2013).

47. K. E. Trenberth, J. Fasullo, J. Geophys. Res. 112, D23107 (2007)

48. G. Villarini et al., J. Clim. 27, 4622-4641 (2014).

49. E. Scoccimarro et al., J. Clim. 27, 4642-4654 (2014).

50. H.-S. Kim et al., J. Clim. 27, 8034-8054 (2014).

51. J. D. Woodruff, J. L. Irish, S. J. Camargo, Nature 504, 44-52 (2013).

52. N. Lin, K. Emanuel, M. Oppenheimer, E. Vanmarcke, Nat. Clim. Change 2, 462-467 (2012).

53. N. Lin, K. Emanuel, Nat. Clim. Change 6, 106-111 (2015).

54. D. T. Resio, J. L. Irish, Curr. Clim. Change Rep. 1, 74-84 (2015)

55. C. W. Landsea, B. A. Harper, K. Hoarau, J. A. Knaff, Science $313,452-454$ (2006).

56. C. W. Landsea, G. A. Vecchi, L. Bengtsson, T. R. Knutson, J. Clim. 23, 2508-2519 (2010)

57. G. A. Vecchi, T. R. Knutson, J. Clim. 24, 1736-1746 (2011).

58. P. J. Klotzbach, C. W. Landsea, J. Clim. 28, 7621-7629 (2015)

59. N. L. Bindoff, P. A. Stott, K. M. AchutaRao, M. R. Allen, N. Gillett, D. Gutzler, K. Hansingo, G. Hegerl, Y. Hu, S. Jain, I. I. Mokhov, J. Overland, J. Perlwitz, R. Sebbari, X. Zhang, "Detection and attribution of climate change: From global to regional," in Climate Change 2013: The Physical Science Basis. Contribution of Working Group I to the Fifth Assessment Report of the Intergovernmental Panel on Climate Change, T. F. Stocker et al., Eds. (Cambridge Univ. Press, 2013), pp. 867-952.

60. P. J. Webster, G. J. Holland, J. A. Curry, H.-R. Chang, Science 309, 1844-1846 (2005)

61. J. B. Elsner, J. P. Kossin, T. H. Jagger, Nature 455, $92-95$ (2008)

62. J. P. Kossin, T. L. Olander, K. R. Knapp, J. Clim. 26, 9960-9976 (2013).

63. K. Emanuel, Nature 436, 686-688 (2005).

64. K. Emanuel, J. Clim. 20, 5497-5509 (2007).

65. G. A. Vecchi, K. L. Swanson, B. J. Soden, Science 322 687-689 (2008).

66. H. A. Ramsay, A. H. Sobel, J. Clim. 24, 183-193 (2011)

67. S. J. Camargo, M. Ting, Y. Kushnir, Clim. Dyn. 40, 1515-1529 (2013).

68. M. E. Mann, K. A. Emanuel, EOS 87, 233, 238, 241 (2006).

69. B. B. B. Booth, N. J. Dunstone, P. R. Halloran, T. Andrews, N. Bellouin, Nature 484, 228-232 (2012).

70. K. Emanuel, S. Solomon, D. Folini, S. Davis, C. Cagnazzo, J. Clim. 26, 2288-2301 (2013).

71. G. A. Vecchi, S. Fueglistaler, I. M. Held, T. R. Knutson, M. Zhao, J. Clim. 26, 3877-3891 (2013).

72. M. Ting, S. J. Camargo, C. Li, Y. Kushnir, J. Clim. 28 , 3926-3942 (2015)

73. G. Holland, C. Bruyère, Clim. Dyn. 42, 617-627 (2014)

74. Materials and methods are available as supplementary materials on Science Online.

75. A. A. Wing, K. Emanuel, S. Solomon, Geophys. Res. Lett. 42 8669-8677 (2015)

76. M. Free, M. Bister, K. Emanuel, J. Clim. 17, 1722-1727 (2004).

77. J. P. Kossin, Bull. Am. Meteorol. Soc. 96, 1089-1096 (2015).

78. S. J. Smith et al., Atmos. Chem. Phys. 11, 1101-1116 (2011).

79. D. T. Shindell et al., Atmos. Chem. Phys. 13, 2653-2689 (2013).

80. B. Stevens, J. Clim. 28, 4794-4819 (2015).

81. D. P. van Vuuren et al., Clim. Change 109, 5-31 (2011).

82. J. P. Kossin, K. A. Emanuel, G. A. Vecchi, Nature 509, 349-352 (2014),

83. J. P. Kossin, K. A. Emanuel, S. J. Camargo, J. Clim. (2016).

84. S. M. Uppala et al., O. J. R. Meteorol. Soc. 131, 2961-3012 (2005).

\section{ACKNOWLEDGMENTS}

A.H.S. thanks J. Kossin, G. Vecchi, and K. Emanuel for helpful discussions. This work was supported by NSF grant AGS-1143959 and Office of Naval Research grant N00014-16-1-2073. A.A.W. is supported by a NSF Atmospheric and Geospace Sciences postdoctoral research fellowship under award no. 1433251.

\section{SUPPLEMENTARY MATERIALS}

www.sciencemag.org/content/353/6296/242/suppl/DC1 Materials and Methods

Supplementary Text

Figs. S1 to S3

References (85-87)

10.1126/science.aaf6574 


\section{Science \IAAAS}

\section{Human influence on tropical cyclone intensity}

Adam H. Sobel, Suzana J. Camargo, Timothy M. Hall, Chia-Ying Lee, Michael K. Tippett and Allison A. Wing (July 14, 2016)

Science 353 (6296), 242-246. [doi: 10.1126/science.aaf6574]

Editor's Summary

This copy is for your personal, non-commercial use only.

Article Tools Visit the online version of this article to access the personalization and article tools:

http://science.sciencemag.org/content/353/6296/242

Permissions Obtain information about reproducing this article:

http://www.sciencemag.org/about/permissions.dtl

Science (print ISSN 0036-8075; online ISSN 1095-9203) is published weekly, except the last week in December, by the American Association for the Advancement of Science, 1200 New York Avenue NW, Washington, DC 20005. Copyright 2016 by the American Association for the Advancement of Science; all rights reserved. The title Science is a registered trademark of AAAS. 